\title{
EDITORIAL
}

\section{LA REVISTA ESPAÑOLA DE SALUD PÚBLICA SE HACE AMIGA DE LOS BOSQUES}

Cristina Pérez Andrés (1) y Miguel Ángel Soto (2)

(1) Comité de redacción de la Revista Española de Salud Pública. Dirección General de Salud Pública. Ministerio de Sanidad y Consumo

(2) Greenpeace España

A partir de este primer número del año 2005 la Revista Española de Salud Pública se va a editar en papel $100 \%$ reciclado postconsumo, siguiendo el ejemplo del proyecto Libros Amigos de los Bosques presentado hace unos meses en España por Greenpeace con el deseo de recabar apoyos del sector editorial y de los autores y autoras que publican en España ${ }^{1}$.

Para fabricar el papel de la revista que tiene en las manos no ha sido necesario cortar árboles, ya que se ha reutilizado fibra procedente de papel recuperado. Además, su fabricación ha gastado menos energía que la fabricación de papel de fibra virgen y el consumo de agua también ha sido menor. Se ha realizado un proceso de destintado pero no ha sido necesario blanquear la fibra de celulosa, por lo que las emisiones a los ríos no han incluido derivados de cloro, muy dañinos para el medio ambiente y la salud pública.

En el año 2002 la producción de libros en España alcanzó 275,6 millones de ejemplares $^{1}$. En el caso de las novelas de ficción la gran mayoría del papel utilizado en España es papel procedente de madera virgen en lugar de utilizar fibra reciclada. Aunque según el informe de la $\mathrm{OCDE}^{2}$ en nuestro país el sector forestal no padece los problemas de otras regiones del mundo, el sector editorial español consume papel o pasta de papel procedente de las polémicas plantaciones de eucaliptos de la península ibérica y también papeles importados de países donde se siguen talando bosques primarios (bosques vírgenes), como Finlandia, Rusia y Canadá ${ }^{3}$. Un total de 76 países han perdido ya todos sus bosques primarios y otros once pueden perderlos en los próximos años. El $78 \%$ de los bosques primarios han sido ya destruidos y el $22 \%$ restante están amenaza$\operatorname{dos}^{4}$. Las causas de esta crisis son diversas y complejas: el avance de la frontera agrícola, la ganadería, la minería, los grandes embalses, la construcción de carreteras y pistas forestales, el crecimiento demográfico y el cambio climático. Pero también la demanda internacional de papel y madera, esto es, la explotación forestal industrial, aparece entre las causas de la pérdida de los bosques ${ }^{4}$. En algunas regiones además, esta explotación es frecuentemente ilegal.

Otra de las principales causas de la deforestación es la pobreza ${ }^{5}$. La pobreza es causa de hambre y los individuos que la padecen están legitimados para conseguir alimentos talando árboles y así tener tierras de cultivo y pastoreo, o para ponerse al servicio de las empresas madereras o mineras que obtienen sus beneficios a costa de su trabajo. Así, no sólo no se eliminan los problemas sino que 
persisten las injusticias vinculadas con ellos ${ }^{6}$. Los países desarrollados deben decidirse a ser solidarios con los países que no lo son para resolver la pobreza en el mundo. Es evidente que las primeras víctimas de cualquier desastre ambiental vuelven a ser las poblaciones pobres, por lo que se encuentran encerradas en un círculo del que jamás podrán salir sin el apoyo de los demás.

La disminución de los bosques contribuye al cambio climático reduciendo la masa boscosa que absorbe el dióxido de carbono, uno de los principales gases con efecto invernadero, cuya concentración actual en la atmósfera es una de las causas de este cambio climático. También provoca el desplazamiento de las poblaciones indígenas, la desaparición de los abastecimientos de agua potable y la pérdida de la biodiversidad. La disminución de los bosques acrecienta los efectos negativos del cambio climático, como son el cambio en el régimen de lluvias creando sequías en unos lugares e inundaciones en otros, desaparición de la retención del agua de los deshielos y de las precipitaciones ${ }^{6}$. Todo ello repercute en la salud del planeta y por lo tanto en la de todas sus poblaciones incluida la humana, a causa de la posibilidad de la reaparición de enfermedades infecciosas y parasitarias ya erradicadas (como puede ocurrir con la malaria en España) y el consiguiente aumento de la morbimortalidad causada por las mismas, y de la causada por los desastres naturales que tienen su origen en el cambio climático.

Por este motivo Greenpeace está invitando al sector editorial a comprometerse con el futuro de los bosques primarios y con la producción sostenible a través de la demanda de productos papeleros con altos requisitos ambientales, como son el papel de fibras recicladas, el papel blanqueado totalmente libre de cloro (TCF) o el papel de fibra virgen con el certificado ecológico FSC. El FSC (Forest Stewardship Council o Consejo de Certificación Forestal) es una organización no gubernamental creada en 1993 para establecer las normas que deberían regir y reunir las organizaciones que certifican la sostenibilidad de los bosques productivos.

El proyecto de Greenpeace se está desarrollando en otros países europeos como Reino Unido, Italia, Holanda o Alemania. En Canadá, país pionero de este proyecto, hay actualmente 35 editoriales comprometidas, cuatro millones y medio de libros impresos en papel amigo de los bosques y 45 escritores comprometidos con el proyecto ${ }^{1}$. La Revista Española de Salud Pública, que en el próximo número editará un monográfico sobre contaminación ambiental, no puede dejar de sumarse a esta iniciativa, contribuyendo con ello a frenar la tala de árboles que la industria papelera ejerce a nivel mundial a lo largo de cada año.

En el ámbito de las revistas científicas actualmente se editan en el mundo unas $24.000^{7}$, de las que 2.613 son españolas ${ }^{8}$. Si de cada una de ellas se editan al menos 4 números al año con unas tiradas por cada uno que aunque es muy variable de unas revistas a otras puede ir desde un millar hasta cientos de miles, calcular el número de árboles necesarios para fabricar el papel imprescindible para su edición es imposible, pero desde luego se puede asumir que son miles y miles. Nadie plantea que la comunicación científica deba dejar de realizarse en forma impresa (aunque la existencia de internet traerá sus variaciones en este aspecto) pero sí que se pueden y se deben utilizar las alternativas que están disponibles desde hace tiempo y que promueven la gestión sostenible de los bosques. Además del reciclaje del papel este desarrollo sostenible incluye la utilización de productos con certificado forestal, como el papel certificado por el FSC, cuando es imprescindible la utilización de papel fabricado con fibra virgen.

No seguir estas alternativas a las actuales pautas de consumo de papel es no tener conciencia ni de especie ni de espacio ni de 
tiempo. Es no pensar en las generaciones futuras que ocuparán el planeta después de nosotros, ni en su salud, ni en sus derechos, ni en el patrimonio que estamos obligados a dejarles porque no es nuestro. Al igual que los que nos antecedieron todos estamos de paso y no nos pertenece ninguno de los recursos que son patrimonio de la humanidad y aún más, de la Naturaleza. Podemos utilizarlos, disfrutar de ellos, consumirlos,... Pero tenemos la obligación de hacerlo de la forma más justa y equitativa posible con los que tendrán derecho a utilizarlos, disfrutarlos y consumirlos después que nosotros.

Según un informe del Worldwatch Institute el consumo de fibra de madera puede ser reducido más del $50 \%$ en los países industrializados, mejorando su empleo, haciéndolo más eficiente y utilizando papel recicla$\mathrm{do}^{9}$. Por eso no nos conformamos con utilizar papel reciclado en la edición de la Revista Española de Salud Pública y desde aquí animamos a los editores de otras revistas y a cualquier persona consumidora de papel a utilizar aquél que en su fabricación respete la gestión sostenible de los bosques en particular y la del medio ambiente en general. Y para que ello sea posible también animamos a todas las personas que lean este editorial a no tirar a la basura el papel desechable de sus domicilios, sino a depositarlo en los lugares destinados a su recogida para su reciclaje. Es más, si tuvieran necesidad de imprimir o fotocopiar este editorial, por favor, háganlo en papel reciclado.

\section{BIBLIOGRAFÍA}

1. Greenpeace. Libros Amigos de los Bosques. Una guía para la industria editorial española sobre las fuentes de suministro de papel respetuosas con los últimos Bosques Primarios del planeta. Madrid: Greenpeace; 2004.

2. OCDE. Análisis de los resultados medioambientales. España. Madrid: Ministerio de Medio Ambiente; 2004.p.97.

3. Alonso MA. Papel y medioambiente. El Ecologista 2004; 42:40-1.

4. Santamarta J. La situación actual de los bosques en el mundo. En: Historia de los bosques. Perlin J. Madrid: Gaia proyecto 2050.p. 481-506.

5. den Ouden B. Pobreza, Derechos Humanos y las consecuencias de la deforestación. Organización de estados iberoamericanos para la educación, la ciencia y la cultura. Citado el 21 de enero de 2005. Disponible en: http://www.campus-oei.org/salactsi/ tef03.htm

6. Consecuencias de la deforestación. En: Deforestación: bosques tropicales en disminución. Red de Asesores Forestales de la Agencia Internacional Canadiense para el desarrollo. Disponible en: http://www.rcfa-cfan.org/spanish/s.issues.12-6.html

7. Fernández E, Giner C, Heras JF. e-revist@s. Plataforma digital de revistas científicas electrónicas españolas y latinoamericanas. Panace@ 2004; 5: 248-251.

8. Directorio de revistas Latindex. Disponible en: http://www.latindex.org

9. Abramovitz JN, Mattoon AT. Paper Cuts: Recovering the Paper Landscape. Washington DC: Wordlwatch Institute; 1999. Worldwatch Paper number 149. 